\title{
Tracking volatile degassing of an explosive, rhyolitic eruption using lithium isotopes
}

\author{
NeukampF, J. ${ }^{1}$, Ellis, B.S. ${ }^{1}$, BOUVIER, A.S. ${ }^{2}$, TOllan,
} P. ${ }^{1}$, Laurent, O. ${ }^{1}$, Ulmer, P. ${ }^{1}$, Magna, T. ${ }^{3}$ BACHMANN,O. ${ }^{1}$

${ }^{1}$ Institute of Geochemistry and Petrology, ETH Zurich, Switzerland; julia.neukampf@erdw.ethz.ch

${ }^{2}$ Institut des Sciences de la Terre, University of Lausanne, Switzerland

${ }^{3}$ Czech Geological Survey, Prague 1, Czech Republic

Lithium ( $\mathrm{Li}$ ) is considered as a "passive" volatile, which can partition into the volatile phase, potentially leading to a isotopic fractionation between melt and vapour phase. Lithium is also one of the most rapidly diffusing elements in melts, making it a powerful tool to estimate timescales of rapid geological processes such as syn- and post-eruptive degassing or fluid-driven reactions. To test the application of $\mathrm{Li}$ to investigatin these processes in detail, we employed SIMS to obtain Li contents and isotope compositions in the high silica Mesa Falls Tuff (MFT, 1.30 Ma) rhyolite, one of three major caldera-forming eruptions in Yellowstone.

The groundmass glass of MFT (35.6-54.8 ppm) has a Li concentration of up to a factor of five lower than quartzhosted melt inclusions (up to $400 \mathrm{ppm}$ ). These melt inclusions exhibit $\delta^{7} \mathrm{Li}$ values as low as $-15.3 \%$. In contrast, the groundmass glass exhibits the highest $\delta^{7} \mathrm{Li}$ values $(5.2-$ $16.2 \%$ ). This indicates a large isotopic fractionation between the entrapment of the melt inclusions and the formation of the groundmass glass as the pyroclasts were quenched following eruption. This confirms that the $>30 \%$ in $\delta^{7} \mathrm{Li}$ difference reflects efficient diffusion of ${ }^{6} \mathrm{Li}$ into the vapour phase during degassing, i.e. $\mathrm{Li}$ isotopic fractionation between vapour phase and melt.

The behaviour of $\mathrm{Li}$ is supported by $\mathrm{Li}$ concentration profiles in plagioclase crystals from MFT that show core-torim $\mathrm{Li}$ depletion (from $\sim 25$ to $\sim 5 \mathrm{ppm}$ ), reflecting syneruptive magmatic degassing. Higher $\delta^{7} \mathrm{Li}$ values in the plagioclase rims (measured by fs-LA-MC-ICPMS) support the interpretation that $\mathrm{Li}$ concentration gradients and $\delta^{7} \mathrm{Li}$ profiles are a result of diffusive fractionation during degassing that occurred within tens of minutes prior to quenching as resolved by diffusion modelling of $\mathrm{Li}$ abundances and isotopic ratios.

Our new data thus confirm the theoretically predicted $\mathrm{Li}$ isotopic fractionation between melt and vapour phase as well as sizeable kinetic effects occurring during volcanic degassing. 